\title{
Growth and rupture of unruptured intracranial aneurysms
}

\author{
Seppo Juvela, MD, PhD \\ Department of Clinical Neurosciences, University of Helsinki, Finland
}

OBJECTIVE Risk factors for growth of unruptured intracranial aneurysms (UIAs) during a lifelong follow-up in relation to subsequent rupture are unknown. The author's aim in this study was to investigate whether risk factors for UIA growth are different for those that lead to rupture than for those that do not.

METHODS The series consists of 87 patients with 111 UIAs diagnosed before 1979, when UIAs were not treated. A total follow-up time of the patients was 2648 person-years for all-cause death and 2182 years when patients were monitored until the first rupture, death due to unrelated causes, or the last contact (annual incidence of aneurysm rupture, 1.2\%). The follow-up time between aneurysm measurements was 1669 person-years. Risk factors for UIA growth were analyzed in relation to subsequent rupture.

RESULTS The median follow-up time between aneurysm measurements was 21.7 years (range 1.2-51.0 years). In 40 of the 87 patients (46\%), the UIAs increased in size $\geq 1 \mathrm{~mm}$, and in 31 patients $(36 \%) \geq 3 \mathrm{~mm}$. All ruptured aneurysms in 27 patients grew during the follow-up of 324 person-years (mean growth rates $6.1 \mathrm{~mm}, 0.92 \mathrm{~mm} /$ year, and $37 \% /$ year), while growth without rupture occurred in 13 patients during 302 follow-up years ( $3.9 \mathrm{~mm}, 0.18 \mathrm{~mm} /$ year, and $4 \% /$ year) and no growth occurred in 47 patients during 1043 follow-up years. None of the 60 patients without aneurysm rupture experienced one during the subsequent 639 follow-up years after the last aneurysm measurement. Independent risk factors for UIA growth ( $\geq 1 \mathrm{~mm}$ ) in all patients were female sex (adjusted OR 3.08, 95\% CI 1.04-9.13) and smoking throughout the follow-up time (adjusted OR $3.16,95 \%$ Cl 1.10-9.10), while only smoking (adjusted OR 4.36, 95\% Cl 1.27-14.99) was associated with growth resulting in aneurysm rupture. Smoking was the only independent risk factor for UIA growth $\geq 3 \mathrm{~mm}$ resulting in aneurysm rupture (adjusted OR 4.03, 95\% $\mathrm{Cl} 1.08-15.07$ ). Cigarette smoking at baseline predicted subsequent UIA growth, while smoking at the end of the follow-up was associated with growth resulting in aneurysm rupture.

CONCLUSIONS Cigarette smoking is an important risk factor for UIA growth, particularly for growth resulting in rupture. Cessation of smoking may reduce the risk of devastating aneurysm growth.

https://thejns.org/doi/abs/10.3171/2018.4.JNS18687

KEYWORDS cigarette smoking; intracranial aneurysm; natural history; risk factors; ruptured aneurysm; subarachnoid hemorrhage; vascular disorders

$\mathrm{S}$ UBARACHNOID hemorrhage (SAH) is a disease with a high case fatality rate. ${ }^{10,21,22}$ General life expectancy has increased, but the incidence of SAH has not. ${ }^{6,19,22}$ The obvious decrease in incidence seen particularly in the younger age groups is probably due to a reduction in cigarette smoking in the general population. ${ }^{19}$

High case fatality is the main reason why unruptured intracranial aneurysms (UIAs) are treated, particularly in patients of working age. ${ }^{7,8,22} \mathrm{In}$ view of the increasing use of MRI for examining symptoms unrelated to UIAs (chronic headache, dizziness, nausea, visual disorders, etc.), asymptomatic UIAs are being detected more frequently. $7,8,22$ As SAH incidence is decreasing and the discovery of UIAs is increasing, the indication for UIA treatment is becoming challenging.

Since the prevalence of aneurysms is not decreasing, ${ }^{23}$ the risk of rupture is probably decreasing, resulting in lower SAH incidence rates. The indications for UIA treatment are already problematic because of a lack of prospective studies on the natural history of UIAs. ${ }^{9}$ Since such stud-

ABBREVIATIONS SAH = subarachnoid hemorrhage; UIA = unruptured intracranial aneurysm.

SUBMITTED March 12, 2018. ACCEPTED April 17, 2018.

INCLUDE WHEN CITING Published online September 14, 2018; DOI: 10.3171/2018.4.JNS18687. 
ies of UIAs are impossible to complete nowadays without treatment selection, interest has been focused on studies of aneurysm growth, assuming this to be a proxy for aneurysm rupture. ${ }^{3,5}$ Most UIA growth studies have also been derived from patient populations with treatment selection bias, however, and most of the growing UIAs in these studies did not rupture..$^{3-5}$

An almost lifelong follow-up cohort of UIAs seen at the Helsinki University Central Hospital was not subject to treatment selection bias and had been considered to be the highest-quality study and to have the least sources of bias of any prospective natural history studies of both UIA rupture and growth., ${ }^{3,5,9}$ This prospective follow-up study investigated whether risk factors for UIA growth are different for those that lead to rupture than for those that do not.

\section{Methods \\ Patient Population}

The series consisted of 87 patients with UIAs diagnosed at the Department of Neurosurgery of Helsinki University Central Hospital between 1956 and 1978, when UIAs were not operated on in Finland. Of the 87 patients with UIAs, $79(89 \%)$ had a prior SAH with multiple aneurysms at baseline. Only the ruptured aneurysm was operated on, and its occlusion without the parent vessel was confirmed by postoperative angiography. ${ }^{10,16}$ The series included patients with angiographic follow-up and also those whose aneurysms were measured at autopsy, since aneurysm size may also be associated with both aneurysm rupture and case fatality after $\mathrm{SAH} .{ }^{10,16}$

All patients gave their written informed consent. Approval for the surveys and follow-up data collection was obtained from the local ethics committee, and all aspects of the study were in compliance with national legislation and the Declaration of Helsinki. ${ }^{15}$

\section{Age and Sex Distributions of Patients With and Without Follow-Up Monitoring of Index Unruptured Aneurysms}

Only 4 of the 142 patients with UIAs diagnosed before 1979 who were alive and had not been examined previously with control angiography failed to report to the outpatient department for CT angiography between 1996 and 1998. These patients were elderly (> 80 years) and/or had a severe incapacitating disease and were duly excluded from the study.

Since the cohort included patients from a time period spanning 22 years (1956-1978), there were a further 51 patients with UIAs who had already died without control angiography, with the vast majority of the deaths due to unrelated causes (see Sensitivity Analysis). As to be expected, these patients who were excluded without a control examination of their UIA (55 of 142) differed from those in the present cohort by virtue of their older age at baseline (mean \pm SD $47.1 \pm 9.2$ vs $38.4 \pm 9.1$ years, $p<0.001$ ).

\section{Follow-Up Methods}

The detailed follow-up protocols were reported previously. ${ }^{9-16}$ Briefly, the follow-up evaluations with reports were based on postal questionnaires and telephone inter- views obtained from patients or proxies every 10 years from the 1960s onward. Fifty-six patients were also examined in the outpatient department during 1996-1998. ${ }^{14,16}$ I personally interviewed the patients using a structured questionnaire, and their cerebral vessels were studied with 3D CTA. The structured questionnaire throughout the follow-up included patient characteristics, previous diseases, hospital visits, medication, and health behavior. In addition, the aneurysm sizes in 43 patients were monitored with conventional or digital angiography $(n=33)$ or at autopsy $(n=10)$ between 1959 and 2008 because of an aneurysm rupture or a need to check the aneurysm status. The last follow-up was performed in 2012.

Additional information on all patients was obtained from medical records supplied by other hospitals and general practitioners, and the accuracy of the medical data, including blood pressure values, was recorded. ${ }^{12-15}$ Autopsy reports and official death certificates were examined for all deceased patients. The follow-up was complete.

\section{Risk Factors}

Blood pressure values were recorded at baseline..$^{13} \mathrm{~A}$ history of hypertension was also defined as a systolic pressure repeatedly $>140 \mathrm{~mm} \mathrm{Hg}$, a diastolic pressure $>90$ $\mathrm{mm} \mathrm{Hg}$, or use of antihypertensive medication., ${ }^{9,12,15}$ Cigarette smoking was grouped as follows: never a smoker, formerly a regular cigarette smoker (quit before or during the follow-up), or currently a cigarette smoker at the end of follow-up, with 10 and 20 cigarettes per day as cutoff points. ${ }^{14-16}$ Alcohol consumption was calculated as approximate grams of absolute ethanol consumed within 1 week ( 1 standard drink $=12 \mathrm{~g}$ of alcohol) throughout the follow-up period..$^{14-16}$ A family history of SAH was defined as $\geq 2$ first-degree relatives with verified ruptured aneurysms.

\section{Aneurysm Measurements}

All angiograms and $\mathrm{CT}$ angiograms were examined by 2 experienced neuroradiologists who had no knowledge of the patients' case histories. ${ }^{11-16}$ Discrepancies were resolved by consensus opinion. The maximum (D), transverse (d), and height (h) diameters of the UIAs together with their neck width (n) were measured from standard projections of $2 \mathrm{D}$ conventional angiograms at baseline and used to calculate the aneurysm following indices: 1) aneurysm volume $\left.\left(\pi \times \mathrm{D} \times \mathrm{d}^{2} / 6\right), 2\right)$ aspect ratio $(\mathrm{D} / \mathrm{n})$, and 3 ) the bottleneck factor $(d / n)$. Also recorded were the location and shape (round, oval, irregular, or lobulate) of the UIA.

Aneurysm growth rates were measured as the difference in the maximum aneurysm diameter between the initial and follow-up angiograms or the initial angiogram and autopsy ${ }^{16}$ The difference in diameter was also divided by the number of follow-up years. The third growth rate variable was the relative difference in diameter per followup year calculated using the following formula: difference in diameter/initial diameter/number of follow-up years. ${ }^{16}$

\section{Statistical Analysis}

The data were analyzed using IBM SPSS Statistics, 
version 24.0 for Windows (IBM Corp.). For univariable statistics, conventional statistical tests were used. For the parametric analyses the values for UIA growth variables were analyzed after square root transformation to obtain a normal distribution of the groups. Univariable associations between parameters were tested using Spearman rank correlation coefficients $\left(r_{\mathrm{s}}\right)$. The average annual growth incidence was calculated by dividing the number of patients with UIA growth by the number of person-years in the measurement follow-up. This probably underestimates the growth rate, particularly among those without any aneurysm rupture, since growth may have occurred years before the follow-up study. Sensitivity analysis was done to calculate UIA growth events according to rupture status in the entire original cohort, including patients without follow-up angiograms.

Univariable and multivariable odds ratios with 95\% confidence intervals for the risk factors, including their interactions, for associations with the occurrence of UIA growth and later rupture, were analyzed by unconditional logistic regression. A maximum-likelihood stepwise forward elimination procedure was used, with selection of the variables to be added on the basis of the magnitudes of their probability values $(\mathrm{p}<0.1)$. Multiple linear regression analyses were performed to establish independent associations between the risk factors and the continuous aneurysm growth rate variables. A 2-tailed $p$ value $<0.05$ was considered statistically significant.

\section{Results}

\section{Patient Characteristics and Follow-Up}

A total follow-up time of the 87 patients was 2648 person-years for all-cause death and 2182 years when patients were monitored until the first rupture, death due to unrelated causes, or the last contact (annual incidence of aneurysm rupture, $1.2 \%$ ). The median follow-up time for aneurysm size per patient was 21.7 years (mean 19.2, range $1.2-51.0$ years). Of the 87 patients, 27 (31\%) experienced SAH during a total follow-up of 1669 measurement person-years. Of SAHs, 10 were fatal. The cumulative rate of SAH at 30 years was $36.9 \%$ (95\% CI $25.5 \%-48.3 \%$ ). The median measurement follow-up time between diagnosis and aneurysm rupture in 27 patients was 10.6 years (mean 12.0, range 1.2-24.1 years), and for the 60 patients without rupture it was 24.1 years (mean 22.4, range 1.351.0 years).

All 27 UIAs that later ruptured had increased in size by at least $1 \mathrm{~mm}$ and 23 had increased in diameter by $\geq 3$ $\mathrm{mm}$. Of the largest UIAs in 60 patients without an aneurysm rupture, 13 increased by $\geq 1 \mathrm{~mm}$ and 8 by $\geq 3 \mathrm{~mm}$. UIA growth with rupture significantly shortened life expectancy (Supplemental Fig. 1). UIAs with both fatal and nonfatal ruptures had similar growth rates.

The baseline characteristics of the patients stratified by aneurysm growth $\geq 1 \mathrm{~mm}$ and rupture status are shown in Table 1. Cigarette smoking at baseline increased UIA growth, and aneurysms were more likely both to grow and to rupture in those who were also smokers at the end of the follow-up period $(\mathrm{p}<0.05)$. Those with UIA growth and rupture also more frequently had very small aneurysms
$(<3 \mathrm{~mm})$ at baseline than others $(\mathrm{p}=0.044)$. Aneurysm diameters of smokers were nonsignificantly smaller than those of others $(4.3 \pm 2.2 \mathrm{~mm}$ vs $5.5 \pm 4.1 \mathrm{~mm}, \mathrm{p}=0.12)$.

The baseline characteristics and aneurysm growth rate variables are compared in Table 2. All growth rate measurements were higher $(\mathrm{p}<0.01)$ in the aneurysms that later ruptured than in those without a rupture, including the nonrupturing growing UIAs. Cigarette smoking was also associated with all the growth rate variables, but the higher growth rates did not reach significance among the women, on account of the fact that there were more male smokers with high UIA growth rates. There were more current smokers among the men than the women both at the baseline (25/34 [74\%] vs 19/47 [40\%], $\mathrm{p}=0.003)$ and at the end of the follow-up (19/34 [56\%] vs $15 / 47$ [32\%], p $=0.031$ ).

The nonparametric correlations between UIA growth rate and other variables are shown in Table 3. Aneurysm growth rates, particularly in relative terms, were inversely correlated with the aneurysm measurement indices since the aneurysms that grew were also more likely to rupture and had a shorter follow-up. The number of cigarettes smoked daily during the follow-up correlated with the aneurysm growth variables $\left(r_{\mathrm{s}}=0.233\right.$ to $0.258, \mathrm{p}=0.024$ to 0.041 ), but when correlation patterns of UIA growth were analyzed separately according to the later rupture status, no correlations were observed in the UIAs that did not rupture (Supplemental Table 1). Nevertheless, the relative aneurysm growth rate in the aneurysms that later ruptured was closely correlated inversely with both the measurement indices and the follow-up times.

\section{Approximate Annual Growth Incidence}

The unruptured aneurysms increased in size by $\geq$ $1 \mathrm{~mm}$ in 40 of the 87 patients (46\%) and by $\geq 3 \mathrm{~mm}$ in 31 patients (36\%). The estimated approximate annual incidence of UIA growth $\geq 1 \mathrm{~mm}$ was $2.4 \%$ and that of growth $\geq 3 \mathrm{~mm}$ was $1.9 \%$. The corresponding annual UIA growth rates in the patients with a later rupture were $8.3 \%$ and $7.1 \%$, respectively, and those in the patients without a rupture were $1.0 \%$ and $0.6 \%$, respectively. Annual growth rate incidences among the current smokers at baseline were $2.8 \%$ and $2.3 \%$ and those of nonsmokers $1.6 \%$ and $1.0 \%$, respectively.

\section{Risk Factors for UIA Growth}

In multiple linear regression analyses, growth was independently predicted by current smoking at baseline (standardized coefficient $0.283, \mathrm{p}=0.015$ ) and female sex $(0.229, \mathrm{p}=0.049)$, while growth rate per year was predicted only by smoking $(0.235, \mathrm{p}=0.048)$ but not by female sex $(0.137, p=0.25)$. Similar results were obtained for the relative growth rate (standardized coefficients $0.237, \mathrm{p}=$ 0.046 and $0.033, \mathrm{p}=0.78$ ).

Current smoking at the end of the follow-up was associated independently with all the growth rate variables (the sex-adjusted standardized regression coefficients ranged from 0.293 to 0.314 and $\mathrm{p}$ value from 0.006 to 0.010). Two-way ANOVA showed that aneurysm rupture was closely associated with all the aneurysm growth rate 
TABLE 1. Baseline characteristics of patients stratified by aneurysm growth and later rupture status

\begin{tabular}{|c|c|c|c|c|}
\hline Characteristic & $\begin{array}{l}\text { Patients w/ SAH \& } \\
\text { UIA Growth }(n=27)\end{array}$ & $\begin{array}{l}\text { Patients w/ UIA Growth } \\
\text { but w/o SAH }(n=13)\end{array}$ & $\begin{array}{c}\text { Patients w/o Aneurysm } \\
\text { Growth or Rupture }(n=47)\end{array}$ & $\begin{array}{l}\text { All Patients } \\
\quad(n=87)\end{array}$ \\
\hline Women (\%) & $19(70)$ & $10(77)$ & $24(51)$ & $53(61)$ \\
\hline Mean age, yrs & $36.5 \pm 8.0$ & $38.4 \pm 6.1$ & $39.5 \pm 10.3$ & $38.4 \pm 9.1$ \\
\hline Mean BMI, kg/m² & $27.2 \pm 4.1$ & $26.4 \pm 4.7$ & $25.9 \pm 4.0$ & $26.3 \pm 4.1$ \\
\hline Mean systolic/diastolic BP, mm Hg & $137 \pm 20 / 82 \pm 9$ & $134 \pm 11 / 83 \pm 5$ & $138 \pm 18 / 86 \pm 10$ & $137 \pm 17 / 84 \pm 9$ \\
\hline History of hypertension, $\mathrm{n}(\%)$ & $10(37)$ & $3(23)$ & $13(28)$ & $26(30)$ \\
\hline \multicolumn{5}{|l|}{ Smoking status, $\mathrm{n}(\%)^{*}$} \\
\hline Nonsmoker & $8(36)$ & $4(31)$ & $14(30)$ & $26(32)$ \\
\hline Quit before FU & 0 & $1(8)$ & $9(20)$ & $10(12)$ \\
\hline Quit during FU & 0 & $3(23)$ & $8(17)$ & $11(14)$ \\
\hline Current smoker & $14(64)$ & $5(39)$ & $15(33)$ & $34(42)$ \\
\hline Heavy smoking during FU (>20 cigarettes/day, \%) & $7 / 20(35)$ & $4 / 13(31)$ & $8 / 44(18)$ & $19 / 77(25)$ \\
\hline \multicolumn{5}{|l|}{ Alcohol consumption (\%) } \\
\hline$<300 \mathrm{~g} / \mathrm{wk}$ & $11(79)$ & $11(92)$ & $38(88)$ & $60(87)$ \\
\hline$\geq 300 \mathrm{~g} / \mathrm{wk}$ & $3(21)$ & $1(8)$ & $5(12)$ & $9(13)$ \\
\hline Prior SAH, n (\%) & $25(93)$ & $12(92)$ & $42(89)$ & $79(91)$ \\
\hline \multicolumn{5}{|l|}{ Family history of ruptured aneurysms, $n(\%)$} \\
\hline No & $14(82)$ & $11(92)$ & $37(90)$ & $62(89)$ \\
\hline Yes & $3(18)$ & $1(8)$ & $4(10)$ & $8(11)$ \\
\hline \multicolumn{5}{|l|}{ Location of largest aneurysm (\%) } \\
\hline ICA, posterior communicating artery & $8(30)$ & $2(15)$ & $8(17)$ & $18(21)$ \\
\hline ICA, bifurcation & $3(11)$ & $1(8)$ & $0(-)$ & $4(5)$ \\
\hline ICA, other & $1(4)$ & $1(8)$ & $11(23)$ & $13(15)$ \\
\hline $\mathrm{ACA}+\mathrm{A}_{2}$ & $1(4)$ & 0 & $3(6)$ & $4(5)$ \\
\hline $\mathrm{ACoA}$ & $2(7)$ & 0 & $1(2)$ & $3(3)$ \\
\hline Middle cerebral artery & $12(44)$ & $9(69)$ & $22(47)$ & $43(49)$ \\
\hline Vertebrobasilar circulation & 0 & 0 & $2(4)$ & $2(2)$ \\
\hline \multicolumn{5}{|l|}{ Diameter of largest aneurysm, $\mathrm{mm}$} \\
\hline Mean & $5.0 \pm 4.7$ & $4.6 \pm 2.0$ & $5.4 \pm 4.1$ & $5.1 \pm 4.1$ \\
\hline \multicolumn{5}{|l|}{$\mathrm{n}(\%)$} \\
\hline$<3$ & $7(26) \dagger$ & $1(8)$ & $3(6)$ & $11(13)$ \\
\hline$<7$ & $22(81)$ & $11(85)$ & $41(87)$ & $74(85)$ \\
\hline$\geq 7$ & $5(19)$ & $2(15)$ & $6(13)$ & $13(15)$ \\
\hline \multicolumn{5}{|l|}{ Vol of largest aneurysm, $\mathrm{mm}^{3}$} \\
\hline Mean & $325 \pm 1497$ & $42 \pm 45$ & $149 \pm 513$ & $187 \pm 910$ \\
\hline Median (IQR) & $14(4-63)$ & $18(7-69)$ & $32(14-63)$ & $20(8-63)$ \\
\hline Mean aspect ratio & $1.7 \pm 1.0$ & $1.6 \pm 0.5$ & $1.7 \pm 0.7$ & $1.7 \pm 0.8$ \\
\hline Mean bottleneck factor & $1.4 \pm 0.8$ & $1.3 \pm 0.5$ & $1.3 \pm 0.5$ & $1.3 \pm 0.6$ \\
\hline \multicolumn{5}{|l|}{ Irregularity or lobulation (\%) } \\
\hline No & $25(93)$ & $10(77)$ & $38(81)$ & $73(84)$ \\
\hline Yes & $2(7)$ & $3(23)$ & $9(19)$ & $14(16)$ \\
\hline \multicolumn{5}{|l|}{ Multiple unruptured aneurysms (\%) } \\
\hline No & $22(81)$ & $11(85)$ & $33(70)$ & $66(76)$ \\
\hline Yes & $5(19)$ & $2(15)$ & $14(30)$ & $21(24)$ \\
\hline
\end{tabular}

$\mathrm{ACA}=$ anterior cerebral artery; $\mathrm{ACOA}=$ anterior communicating artery; $\mathrm{BP}=$ blood pressure; $\mathrm{FU}=$ follow-up.

Mean values are presented as the mean \pm SD.

${ }^{*} p<0.05$ for unruptured aneurysms of cigarette smokers at baseline, which grew more during the follow-up, while aneurysms were more likely to grow and rupture in those who were also smokers at the end of the follow-up period.

$t p<0.05$. Patients with aneurysm growth and rupture more frequently had very small aneurysms $(<3 \mathrm{~mm})$ at baseline. 
TABLE 2. Patient characteristics and growth rate variables

\begin{tabular}{|c|c|c|c|}
\hline \multirow[b]{2}{*}{ Characteristic } & \multicolumn{3}{|c|}{ Growth in Aneurysm Diameter* } \\
\hline & $\mathrm{mm}$ & $\mathrm{mm} / \mathrm{Yr}$ & $\% / Y r \dagger$ \\
\hline All patients $(n=87$ ) & $2.5 \pm 3.7 ; 0(4.0)$ & $0.3 \pm 0.9 ; 0(0.2)$ & $12 \pm 43 ; 0(7)$ \\
\hline \multicolumn{4}{|l|}{ Sex } \\
\hline Men $(n=34)$ & $1.9 \pm 3.4 ; 0(3.3)$ & $0.3 \pm 1.2 ; 0(0.2)$ & $19 \pm 65 ; 0$ (4) \\
\hline Women $(n=53)$ & $2.8 \pm 3.9 ; 1.0(5.0)$ & $0.3 \pm 0.5 ; 0.06(0.4)$ & $8 \pm 16 ; 1(8)$ \\
\hline \multicolumn{4}{|l|}{ History of hypertension } \\
\hline No $(n=61)$ & $2.3 \pm 3.6 ; 0(4.0)$ & $0.2 \pm 0.4 ; 0(0.2)$ & $6 \pm 21 ; 0(5)$ \\
\hline Yes $(n=26)$ & $3.0 \pm 4.1 ; 0.5(5.0)$ & $0.6 \pm 1.4 ; 0.1(0.5)$ & $26 \pm 70 ; 2(16)$ \\
\hline \multicolumn{4}{|l|}{ Current smoker at baseline } \\
\hline No $(n=37)$ & $1.4 \pm 2.5 ; 0(2.0)$ & $0.2 \pm 0.4 ; 0(0.1)$ & $3 \pm 8 ; 0(2)$ \\
\hline Yes $(n=44)$ & $3.1 \pm 4.5 ; 0.5(5.0) \ddagger$ & $0.4 \pm 1.1 ; 0.03(0.2)$ & $19 \pm 58 ; 0.4(7) \ddagger$ \\
\hline \multicolumn{4}{|l|}{ Current smoker at end of FU } \\
\hline No $(n=47)$ & $1.6 \pm 2.7 ; 0(2.0)$ & $0.1 \pm 0.4 ; 0(0.1)$ & $3 \pm 8 ; 0(2)$ \\
\hline Yes $(n=34)$ & $3.4 \pm 4.7 ; 1.5(5.0) \ddagger$ & $0.5 \pm 1.3 ; 0.1(0.3) \ddagger$ & $24 \pm 66 ; 2(12) \ddagger$ \\
\hline \multicolumn{4}{|l|}{ Alcohol consumption, g/wk } \\
\hline$<300(n=60)$ & $1.7 \pm 2.9 ; 0(2.8)$ & $0.3 \pm 1.0 ; 0(0.1)$ & $12 \pm 50 ; 0$ (3) \\
\hline$\geq 300(n=9)$ & $2.1 \pm 3.1 ; 0(5.5)$ & $0.2 \pm 0.3 ; 0(0.4)$ & $14 \pm 28 ; 0$ (15) \\
\hline \multicolumn{4}{|l|}{ Family history of ruptured aneurysms } \\
\hline No $(n=62)$ & $2.2 \pm 3.6 ; 0(4.3)$ & $0.3 \pm 0.9 ; 0(0.2)$ & $12 \pm 49 ; 0(5)$ \\
\hline Yes $(n=8)$ & $2.6 \pm 3.3 ; 1.5(4.8)$ & $0.2 \pm 0.2 ; 0.6(0.3)$ & $7 \pm 12 ; 1(11)$ \\
\hline \multicolumn{4}{|l|}{ Location of largest aneurysm§ } \\
\hline ICA, posterior communicating artery $(n=18)$ & $2.6 \pm 2.9 ; 1.5(4.3)$ & $0.6 \pm 1.7 ; 0.1(0.4)$ & $27 \pm 82 ; 3(10)$ \\
\hline ICA, bifurcation $(n=4)$ & $6.0 \pm 3.9 ; 6.5(7.5) \ddagger$ & $0.9 \pm 0.9 ; 0.6(1.6) \ddagger$ & $17 \pm 21 ; 7(33) \ddagger$ \\
\hline ICA, other $(n=13)$ & $1.4 \pm 4.7 ; 0(0)$ & $0.1 \pm 0.3 ; 0(0)$ & $1 \pm 3 ; 0(0)$ \\
\hline$A C A+A_{2}(n=4)$ & $1.3 \pm 2.5 ; 0(3.8)$ & $0.1 \pm 0.1 ; 0(0.2)$ & $2 \pm 4 ; 0(6)$ \\
\hline $\operatorname{ACoA}(n=3)$ & $3.0 \pm 3.6 ; 2.0(-)$ & $0.3 \pm 0.5 ; 0.1(-)$ & $30 \pm 50 ; 2(-)$ \\
\hline Middle cerebral artery $(n=43)$ & $2.7 \pm 3.8 ; 0(5.0)$ & $0.2 \pm 0.4 ; 0(0.3)$ & $9 \pm 25 ; 0(6)$ \\
\hline Vertebrobasilar circulation $(n=2)$ & 0 & 0 & 0 \\
\hline \multicolumn{4}{|l|}{ Diameter of largest aneurysm, mm } \\
\hline$<7(n=74)$ & $2.3 \pm 3.4 ; 0(4.0)$ & $0.3 \pm 0.9 ; 0(0.2)$ & $14 \pm 46 ; 0$ (8) \\
\hline$\geq 7(n=13)$ & $3.5 \pm 5.1 ; 1.0(6.5)$ & $0.3 \pm 0.6 ; 0.1(0.4)$ & $3 \pm 4 ; 1(5)$ \\
\hline \multicolumn{4}{|l|}{ Irregularity or lobulation } \\
\hline No $(n=73)$ & $2.8 \pm 4.0 ; 0(5.0)$ & $0.4 \pm 0.9 ; 0(0.3)$ & $14 \pm 46 ; 0$ (8) \\
\hline Yes $(n=14)$ & $1.1 \pm 1.6 ; 0(2.3)$ & $0.1 \pm 0.2 ; 0(0.1)$ & $1 \pm 3 ; 0(2)$ \\
\hline \multicolumn{4}{|l|}{ Multiple unruptured aneurysms } \\
\hline No $(n=66)$ & $2.7 \pm 3.8 ; 0.5(5.0)$ & $0.2 \pm 0.4 ; 0.02(0.3)$ & $8 \pm 18 ; 0.4(8)$ \\
\hline Yes $(n=21)$ & $2.0 \pm 3.6 ; 0(2.5)$ & $0.6 \pm 1.6 ; 0(0.1)$ & $25 \pm 81 ; 0$ (3) \\
\hline \multicolumn{4}{|l|}{ Later aneurysm ruptureף } \\
\hline Neither growth nor rupture $(n=47)$ & 0 & 0 & 0 \\
\hline Aneurysm growth w/o rupture $(n=13)$ & $3.9 \pm 2.4 ; 4(3)$ & $0.2 \pm 0.1 ; 0.2(0.2)$ & $4 \pm 3 ; 4(4)$ \\
\hline Aneurysm growth \& rupture $(n=27)$ & $6.1 \pm 4.2 ; 5.0(4.0) \ddagger$ & $0.9 \pm 1.4 ; 0.4(0.8)^{\star *}$ & $37 \pm 71 ; 12(27)^{\star *}$ \\
\hline
\end{tabular}

Values are means $\pm S D$; medians $(I Q R)$.

* Growth $(p=0.10)$, growth rate per year $(p=0.078)$, and relative growth rate $(p=0.097)$ tended to be higher in women than in men.

$\dagger$ Relative growth of aneurysm (\%/year) $=$ relative change in maximum diameter per follow-up year (growth of diameter/initial diameter/follow-up time in years).

$\ddagger p<0.05$.

§ ICA bifurcation versus ICA aneurysms other than a posterior communicating artery aneurysm.

I Aneurysm rupture versus aneurysm growth without a rupture and for aneurysm location.

${ }_{* *}^{*} p<0.01$. 


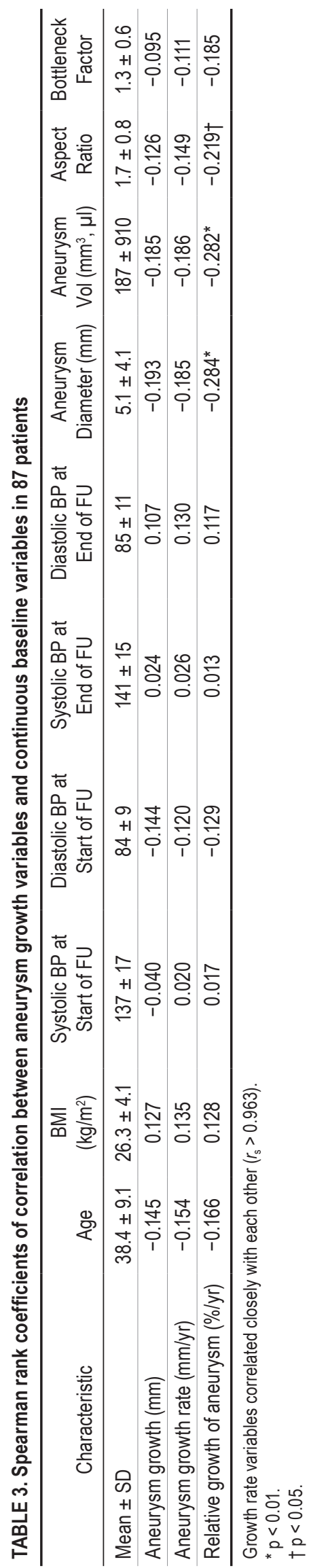

variables (Supplemental Tables 2 and 3). Furthermore, current smoking both at baseline and at the end of follow-up was associated with relative growth rate independently of aneurysm rupture status. There was also a significant interaction $(\mathrm{p}<0.05)$ between rupture status and smoking in affecting relative growth rate, showing that smoking hastened more relative growth in the aneurysms that ruptured.

Logistic regression models for factors associated with an aneurysm growth of at least $1 \mathrm{~mm}$ during the follow-up, as shown Table 4, suggest that both female sex and smoking throughout the follow-up time were independently associated with aneurysm growth, but that only smoking was associated with growth leading to rupture. No factors were associated with growth in aneurysms that did not rupture. The same models with use of an aneurysm growth of at least $3 \mathrm{~mm}$ versus no growth are shown in Table 5 . Use of UIA diameter $\geq 3 \mathrm{~mm}$ versus $<3 \mathrm{~mm}$ instead of $\geq 7 \mathrm{~mm}$ versus $<7 \mathrm{~mm}$ as cutoff points did not affect the results.

\section{Sensitivity Analysis}

Of 87 patients, 27 (31\%) with UIA growth $\geq 1 \mathrm{~mm}$ had an aneurysm rupture and $13(15 \%)$ had growth without a rupture, while 47 (54\%) had no growth. Of the initial cohort of 142 patients, 55 had missing control examinations, which had accumulated more frequently among patients without a later aneurysm rupture than in those with a rupture (48/108 vs 7/34). If the missing values for the growth of nonruptured UIAs were replaced by the same proportion seen in those without missing values, there would be 23 cases with UIA growth but without SAH and 85 cases without growth. All 34 patients with an aneurysm rupture would be expected to have a growth of $\geq 1 \mathrm{~mm}$, since all 27 measured ruptured aneurysms had grown by $\geq 1 \mathrm{~mm}$. Of the 57 patients with UIA growth $\geq 1 \mathrm{~mm}, 34(60 \%)$ would have had a rupture.

Out of 31 patients with UIA growth $\geq 3 \mathrm{~mm}, 23$ (74\%) had an aneurysm rupture and $8(26 \%)$ did not. If the missing values for the growth of nonruptured UIA were replaced by the same proportion, there would be 14 cases with UIA growth $\geq 3 \mathrm{~mm}$ but without SAH and 94 cases without such growth. Of the 34 patients with an aneurysm rupture, 29 would be expected to have a growth of $\geq 3 \mathrm{~mm}$, since 23 of 27 measured ruptured aneurysms had grown by $\geq 3 \mathrm{~mm}$. Of the 43 patients with UIA growth $\geq 3 \mathrm{~mm}$, $29(67 \%)$ would have had a rupture. Aneurysm growth of both $\geq 1 \mathrm{~mm}$ and $\geq 3 \mathrm{~mm}$ was closely associated with aneurysm rupture $(\mathrm{p}<0.001)$. The OR for rupture in the presence of growth $\geq 3 \mathrm{~mm}$ was 39 (95\% CI 13-117).

\section{Discussion}

This study suggests that aneurysm growth seems to entail different risk factors according to the later rupture status. While female sex and cigarette smoking seem to be risk factors for UIA growth, only smoking seems to be a risk factor for growth leading to rupture. Smoking also seems to hasten the growth of aneurysms that are prone to rupture. Two-thirds of the aneurysms that had grown by at least $3 \mathrm{~mm}$ had ruptured.

It was concluded in 2 recent meta-analyses of aneurysm growth that female sex, cigarette smoking at base- 
TABLE 4. Multivariable odds ratios of risk factors for aneurysm growth ( $\geq 1 \mathrm{~mm}$ )

\begin{tabular}{|c|c|c|c|c|c|c|}
\hline & \multicolumn{2}{|c|}{ Model I } & \multicolumn{2}{|c|}{ Model II } & \multicolumn{2}{|c|}{ Model III } \\
\hline & Univariable & Multivariable & Univariable & Multivariable & Univariable & Multivariable \\
\hline Female sex & $2.53(1.03-6.21)^{*}$ & $3.08(1.04-9.13)^{*}$ & $2.28(0.83-6.22)$ & $2.64(0.73-9.49)$ & $3.19(0.78-13.10)$ & $3.37(0.76-15.02)$ \\
\hline Age at diagnosis (per $10 \mathrm{yrs}$ ) & $0.75(0.46-1.20)$ & $0.72(0.41-1.26)$ & $0.71(0.43-1.20)$ & $0.64(0.34-1.24)$ & $0.88(0.46-1.69)$ & $0.91(0.46-1.80)$ \\
\hline Smoking throughout FU & $2.45(0.99-6.08)$ & $3.16(1.10-9.10)^{*}$ & $3.62(1.25-10.49)^{*}$ & $4.36(1.27-14.99)^{*}$ & $1.29(0.36-4.63)$ & $1.47(0.36-5.95)$ \\
\hline Systolic BP (per 10 mm Hg) & $0.92(0.72-1.18)$ & $1.01(0.77-1.33)$ & $0.96(0.74-1.25)$ & $1.07(0.79-1.45)$ & $0.83(0.54-1.29)$ & $0.91(0.59-1.42)$ \\
\hline Aneurysm in $\mathrm{ACoA}$ & $2.42(0.21-27.74)$ & $2.58(0.20-33.45)$ & $3.68(0.32-42.62)$ & $5.02(0.34-73.87)$ & NA & NA \\
\hline $\begin{array}{l}\text { Maximum diameter of unrup- } \\
\text { tured aneurysm }(\geq 7 \mathrm{~mm})\end{array}$ & $1.45(0.44-4.73)$ & $2.00(0.51-7.82)$ & $1.55(0.43-5.67)$ & $2.48(0.53-11.71)$ & $1.24(0.22-7.03)$ & $1.39(0.21-8.93)$ \\
\hline
\end{tabular}

NA = not available.

Values are ORs and 95\% Cls. Model I: risk of aneurysm growth for all patients; model II: risk of aneurysm growth leading to its rupture compared with those without aneurysm growth; and model III: risk of aneurysm growth but without a rupture compared with those without aneurysm growth.

${ }^{*} p<0.05$

line, aneurysm size, posterior circulation aneurysms, and possibly age, hypertension, and aneurysm multiplicity may increase the risk of UIA growth, while prior SAH and a family history of aneurysms do not. ${ }^{3,5}$ There was substantial heterogeneity for risk factors between studies, except for sex, smoking at baseline, and hypertension. The results of these meta-analyses were subject to treatment selection of UIAs and publication bias.

In the past, follow-up angiograms were principally obtained in patients after an aneurysm rupture, resulting in the assumption that aneurysms may grow more frequently than happens in reality. Recently, follow-up examinations have been carried out for quite the opposite reasons, for patients with a conservative follow-up of a UIA with a low rupture risk. ${ }^{3,5}$ High-risk UIAs (large or growing UIAs in younger patients and smokers) are usually treated at baseline without any follow-up., ${ }^{9,20,24}$

The present study with an almost lifelong follow-up of UIA patients also included patients with a high UIA rupture risk. Previously published results from this study ${ }^{16}$ have been reported to have the best data quality and the lowest bias of all UIA growth studies to date, despite reporting the lowest approximate annual incidence of growth. ${ }^{3,5}$ In the meta-analyses, the growth in different studies was defined as the incidence of $\geq 0.5$ - to 2 -mm increases in maximum diameter. This growth incidence does not take into account the true growth rate $(\mathrm{mm}, \mathrm{mm} / \mathrm{year}$, or relative growth/ year). A false positive of 1-mm growth is more likely to occur in a large $20-\mathrm{mm}$ aneurysm than in a $3-\mathrm{mm}$ one.

The size of the aneurysm is important for the risk of rupture, , $15,20,24$ since the tension of the aneurysm wall is directly related to the diameter of the aneurysm and the intraaneurysmal pressure and inversely related to the thickness of the wall, in accordance with Laplace's law. ${ }^{16,21}$ Tension in the wall (within the wall of a sphere) can be calculated from the following formula: pressure $\times$ radius $/(2 \times$ thickness). Similar growth in UIAs increases the relative tension and growth rate more in small UIAs than in large ones. The relative growth rate, which took into account the initial aneurysm diameter, was inversely associated with the aneurysm size parameters, particularly in those aneurysms that ruptured. This suggests a concept in which the relative aneurysm growth rate per year of follow-up is closely associated with an increase in wall tension and the risk of a rupture. This supports also the concept that small ruptured aneurysms may have grown and ruptured within a relative short time after their formation when compared with larger ones.

The aneurysm growth rate is not consistent and can vary considerably without any clear predictors during a long-

TABLE 5. Multivariable odds ratios of risk factors for aneurysm growth ( $\geq 3 \mathrm{~mm}$ )

\begin{tabular}{|c|c|c|c|c|c|c|}
\hline & \multicolumn{2}{|c|}{ Model I } & \multicolumn{2}{|c|}{ Model II } & \multicolumn{2}{|c|}{ Model III } \\
\hline & Univariable & Multivariable & Univariable & Multivariable & Univariable & Multivariable \\
\hline Women & $2.01(0.78-5.18)$ & $2.26(0.73-6.99)$ & $2.19(0.76-6.30)$ & $2.31(0.62-8.54)$ & $1.60(0.34-7.46)$ & $1.90(0.37-9.63)$ \\
\hline Age at diagnosis (per $10 \mathrm{yrs}$ ) & $0.72(0.43-1.20)$ & $0.69(0.38-1.27)$ & $0.70(0.41-1.20)$ & $0.62(0.31-1.23)$ & $0.87(0.39-1.92)$ & $0.95(0.41-2.19)$ \\
\hline Smoking throughout FU & $2.82(1.04-7.60)^{*}$ & $3.54(1.13-11.14)^{*}$ & $3.25(1.05-10.06)^{*}$ & $4.03(1.08-15.07)^{*}$ & $2.07(0.45-9.42)$ & $2.23(0.43-11.61)$ \\
\hline Systolic BP (per $10 \mathrm{~mm} \mathrm{Hg}$ ) & $0.98(0.76-1.27)$ & $1.07(0.80-1.43)$ & $1.00(0.76-1.31)$ & $1.11(0.81-1.52)$ & $0.91(0.56-1.48)$ & $0.99(0.60-1.63)$ \\
\hline Aneurysm in $\mathrm{ACoA}$ & $1.53(0.92-25.46)$ & $1.08(0.59-19.85)$ & $2.09(0.13-35.01)$ & $1.65(0.09-31.14)$ & NA & NA \\
\hline $\begin{array}{l}\text { Maximum diameter of unrup- } \\
\text { tured aneurysm ( } \geq 7 \mathrm{~mm})\end{array}$ & $1.31(0.36-4.75)$ & $2.09(0.48-9.21)$ & $1.44(0.36-5.70)$ & $2.54(0.50-12.91)$ & $0.97(0.10-9.39)$ & $1.10(0.11-11.55)$ \\
\hline
\end{tabular}

Values are ORs and $95 \% \mathrm{Cls}$. Model I: risk of aneurysm growth $\geq 3 \mathrm{~mm}$ for all patients compared with those without aneurysm growth; model II: risk of aneurysm growth $\geq 3 \mathrm{~mm}$ leading to its rupture compared with those without aneurysm growth; model III: risk of aneurysm growth $\geq 3$ mm but without a rupture compared with those without aneurysm growth.

${ }^{*} p<0.05$ 
term follow-up. ${ }^{1}$ The optimal angiographic follow-up interval for monitoring the growth rate is also unclear., ${ }^{1,11}$ The authors did not recommend surveillance imaging of UIA growth as a means of deciding on treatment. Although the aneurysm size of ruptured and unruptured intracranial aneurysms was not associated with growth rate, aneurysms $<7 \mathrm{~mm}$ had higher relative growth rates, particularly in the younger age groups. ${ }^{1}$ The results of that study and the present one conflict somewhat with the growth incidence results reported in the meta-analyses.

Although growth of an aneurysm is not the same thing as its rupture, a few studies have reported a close association between these variables. ${ }^{5}$ According to the present results, the association between aneurysm growth and rupture was also a close one. The OR of UIA growth $\geq 3 \mathrm{~mm}$ for rupture was 39 (sensitivity analysis). If smoking were to continue throughout the follow-up period, the ensuing growth would also result in an increased risk of rupture, whereas cessation of smoking during the follow-up also reduced the rupture risk even though the UIAs had already grown. This is a new observation. There was also an additive interaction between current smoking and aneurysm rupture affecting the relative growth rate, suggesting that smoking particularly increases the growth of small aneurysms.

The present findings are also supported by the result of a recent study of SAH incidence that shows it to decrease simultaneously with smoking prevalence. ${ }^{19}$ Smoking is the most important modifiable risk factor for $\mathrm{SAH},{ }^{2}$ and the slightly higher aneurysm prevalence of smokers does not explain their higher SAH risk. ${ }^{17}$

Despite the discovery of increasing numbers of UIAs, the indications for their treatment are likely to decrease because of the lowered prevalence of smoking and the discovery of incidental UIAs in older people. Existing aneurysms are less likely to rupture in the future if smoking decreases further. Cessation of smoking may even be a treatment option, particularly in men. ${ }^{18}$ Women are known to have a higher incidence of SAH than men, partly because they have a higher aneurysm prevalence (approximately 1.6 -fold). ${ }^{17,23}$

The strengths of this study include the complete and almost lifelong follow-up of patients of working age and the very limited treatment selection bias. ${ }^{11,15}$ Correspondingly, a previous aneurysm growth study based on this cohort ${ }^{16}$ was considered to be of high study quality with low sources of bias relative to other UIA growth studies., ${ }^{3,5}$ This was the only one with a score of 9 (range 0-9) according to the Newcastle Ottawa Scale for cohort studies, where higher scores indicate higher quality. ${ }^{3}$

In this study, all initial UIA measurements were obtained from 2D conventional angiograms, which may yield less accurate measures than $3 \mathrm{D}$ angiograms. For UIA growth measurement, the same projections were done as those for the initial angiograms. Use of UIA growth as a continuous variable and of parametric statistical analyses also decreased source of bias. Finnish people have been considered to be subject to a higher risk of aneurysm rupture, ${ }^{9}$ although the Finnish cohort was the only one in that meta-analysis representing a true natural history of the condition. The incidence of SAH is no higher in Finland than elsewhere when standardized for the study design with its inclusion and exclusion criteria, the accuracy of diagnosis, and the sex and age distributions of the population..$^{19}$

\section{Conclusions}

Although women and active smokers have a higher risk of UIA growth, smoking only increased the growth rate resulting in more frequent ruptures. Cessation of smoking is important, and it may sometimes be the only means required for treating UIA.

\section{Acknowledgments}

This work was supported in part by a research grant to Dr. Juvela from the Paavo Nurmi Foundation.

\section{References}

1. Allcock JM, Canham PB: Angiographic study of the growth of intracranial aneurysms. J Neurosurg 45:617-621, 1976

2. Andreasen TH, Bartek J Jr, Andresen M, Springborg JB, Romner B: Modifiable risk factors for aneurysmal subarachnoid hemorrhage. Stroke 44:3607-3612, 2013

3. Backes D, Rinkel GJ, Laban KG, Algra A, Vergouwen MD: Patient- and aneurysm-specific risk factors for intracranial aneurysm growth: systematic review and meta-analysis. Stroke 47:951-957, 2016

4. Bor AS, Tiel Groenestege AT, terBrugge KG, Agid R, Velthuis BK, Rinkel GJ, et al: Clinical, radiological, and flow-related risk factors for growth of untreated, unruptured intracranial aneurysms. Stroke 46:42-48, 2015

5. Brinjikji W, Zhu YQ, Lanzino G, Cloft HJ, Murad MH, Wang Z, et al: Risk factors for growth of intracranial aneurysms: a systematic review and meta-analysis. AJNR Am J Neuroradiol 37:615-620, 2016

6. de Rooij NK, Linn FHH, van der Plas JA, Algra A, Rinkel GJE: Incidence of subarachnoid haemorrhage: a systematic review with emphasis on region, age, gender and time trends. J Neurol Neurosurg Psychiatry 78:1365-1372, 2007

7. Etminan N, Beseoglu K, Barrow DL, Bederson J, Brown RD Jr, Connolly ES Jr, et al: Multidisciplinary consensus on assessment of unruptured intracranial aneurysms: proposal of an international research group. Stroke 45:1523-1530, 2014

8. Etminan N, Brown RD Jr, Beseoglu K, Juvela S, Raymond J, Morita A, et al: The unruptured intracranial aneurysm treatment score: a multidisciplinary consensus. Neurology 85:881-889, 2015

9. Greving JP, Wermer MJH, Brown RD Jr, Morita A, Juvela $\mathrm{S}$, Yonekura M, et al: Development of the PHASES score for prediction of risk of rupture of intracranial aneurysms: a pooled analysis of six prospective cohort studies. Lancet Neurol 13:59-66, 2014

10. Juvela S: Prehemorrhage risk factors for fatal intracranial aneurysm rupture. Stroke 34:1852-1857, 2003

11. Juvela S, Korja M: Intracranial aneurysm parameters for predicting a future subarachnoid hemorrhage: a long-term follow-up study. Neurosurgery 81:432-440, 2017

12. Juvela S, Lehto H: Risk factors for all-cause death after diagnosis of unruptured intracranial aneurysms. Neurology 84:456-463, 2015

13. Juvela S, Porras M, Heiskanen O: Natural history of unruptured intracranial aneurysms: a long-term follow-up study. J Neurosurg 79:174-182, 1993

14. Juvela S, Porras M, Poussa K: Natural history of unruptured intracranial aneurysms: probability of and risk factors for aneurysm rupture. J Neurosurg 93:379-387, 2000

15. Juvela S, Poussa K, Lehto H, Porras M: Natural history of 
unruptured intracranial aneurysms: a long-term follow-up study. Stroke 44:2414-2421, 2013

16. Juvela S, Poussa K, Porras M: Factors affecting formation and growth of intracranial aneurysms: a long-term follow-up study. Stroke 32:485-491, 2001

17. Kang HG, Kim BJ, Lee J, Kim MJ, Kang DW, Kim JS, et al: Risk factors associated with the presence of unruptured intracranial aneurysms. Stroke 46:3093-3098, 2015

18. Korja M, Lehto H, Juvela S: Lifelong rupture risk of intracranial aneurysms depends on risk factors: a prospective Finnish cohort study. Stroke 45:1958-1963, 2014

19. Korja M, Lehto H, Juvela S, Kaprio J: Incidence of subarachnoid hemorrhage is decreasing together with decreasing smoking rates. Neurology 87:1118-1123, 2016

20. Morita A, Kirino T, Hashi K, Aoki N, Fukuhara S, Hashimoto N, et al: The natural course of unruptured cerebral aneurysms in a Japanese cohort. N Engl J Med 366:2474-2482, 2012

21. Nieuwkamp DJ, Setz LE, Algra A, Linn FHH, de Rooij NK, Rinkel GJE: Changes in case fatality of aneurysmal subarachnoid haemorrhage over time, according to age, sex, and region: a meta-analysis. Lancet Neurol 8:635-642, 2009

22. Steiner T, Juvela S, Unterberg A, Jung C, Forsting M, Rinkel G: European Stroke Organization guidelines for the management of intracranial aneurysms and subarachnoid haemorrhage. Cerebrovasc Dis 35:93-112, 2013

23. Vlak MHM, Algra A, Brandenburg R, Rinkel GJE: Prevalence of unruptured intracranial aneurysms, with emphasis on sex, age, comorbidity, country, and time period: a systematic review and meta-analysis. Lancet Neurol 10:626-636, 2011
24. Wiebers DO, Whisnant JP, Huston J III, Meissner I, Brown RD Jr, Piepgras DG, et al: Unruptured intracranial aneurysms: natural history, clinical outcome, and risks of surgical and endovascular treatment. Lancet 362:103-110, 2003

\section{Disclosures}

The author reports no conflict of interest concerning the materials or methods used in this study or the findings specified in this paper.

\section{Supplemental Information \\ Online-Only Content}

Supplemental material is available with the online version of the article.

Supplemental Figure and Tables. https://thejns.org/doi/suppl/ 10.3171/2018.4.JNS18687.

\section{Correspondence}

Seppo Juvela: University of Helsinki, Finland. seppo.juvela@ helsinki.fi. 